CALEI-

DOSCOPIO

35 / 36

⿶凵8

JULIO - DICIEMBRE 2016

ENERO - JUNIO 2017

\section{Excélsior y la campaña electoral \\ de Álvaro Obregón, 1919-1920}

El periódico es una tienda en que se venden al público las palabras del mismo color que las quiere.

Honore de Balzac

RESUMEN

Este artículo examina la relación entre Álvaro Obregón y la prensa de la Ciudad de México, particularmente con el diario Excélsior, durante la campaña electoral de 1919 a 1920. Durante los meses de octubre de 1919 a septiembre de 1920, periodo en el que sucedieron los eventos de la rebelión de Agua Prieta a la elección de Álvaro Obregón como presidente, el panorama político en México cambió. La llegada de la clase política sonorense al poder, mediante un golpe de Estado, fue justificada por la prensa. Excélsior jugó un papel importante en la construcción de una opinión pública favorable del candidato presidencial Obregón, avalando las acciones que lo llevaron al poder.

Palabras clave: Excélsior, opinión pública, campaña electoral, periodismo, rebelión de Agua Prieta.

1 Egresado de la maestría en Humanidades, línea de Historia de la Universidad Autónoma Metropolitana, Unidad Iztapalapa. 
This article examines the relationship between Álvaro Obregón and the press of the city of Mexico, particularly with the journal Excélsior, during the electoral campaign from 1919 to 1920. During the months of October 1919 to September 1920, a period in which the events occurred the rebellion of Agua Prieta to the election of Álvaro Obregón as president, the political landscape in Mexico changed. The arrival of the Sonoran political class to power through a coup was justified by the press. Excélsior played an important role in building a favorable public opinion of presidential candidate Obregon, endorsing the actions that brought him to power.

Keywords: Excélsior, public opinion, electoral campaing, press, Agua Prieta rebellion.

\section{INTRODUCCIÓN}

En México se puede encontrar que la prensa tiene características de diversa índole. Una de ellas es el regionalismo, condición que le imprime a cada publicación periódica características diferentes; de tal forma que existe una enorme cantidad de material hemerográfico del siglo XIX y principios del xx disperso en los estados de la República. Por esta razón, existen diferencias importantes en los materiales hemerográficos en las distintas regiones de México, los procesos de producción, la distribución, los contenidos y los patrones de centralización, así como en los factores que inciden en la aparición y desaparición de los periódicos. ${ }^{2}$

Si bien la prensa se encarga de hacernos saber el sentir socio-político y cultural del momento, se configura como un documento fundamental para entender el proceso histórico, sobre todo, en la época contemporánea. El análisis de la prensa mexicana nos indica que se debe a un sector social determinado, muchas de las veces a una clase en específico. ${ }^{3}$

2 Covo, Jacqueline, "La prensa en la Historiografía mexicana: problemas y perspectivas", Revista Historia Mexicana, México, Colegio de México, vol. XLII, núm. 3, 1993, p. 701. Un análisis más reciente puede encontrarse en Del Palacio, Celia, "Cómo hacer historia de la prensa sin claudicar en el intento. Formas de hacer historia de la prensa en México", Acervos, México, AGN, núm. 30, otoño 2006-primavera 2007, pp. 4-14.

3 Matute, Álvaro, "Prensa, sociedad y política (1911-1916)", en Cano, Aurora (coord.), Las publicaciones periódicas y la historia de México (ciclo de conferencias), México, UNAM, 1995, p. 64. 
La prensa cumple con un fin político a la vez que tiene una función social. Tiene sus consumidores y les otorga la información por ellos requerida, por eso hay varios tipos de periódicos, como los de nota política o nota roja. Contiene indicadores económicos, además de recreación y pasatiempos, como espectáculos, productos y oferta de empleos. Es decir, es una muestra de la vida social en su conjunto humano. Por todo esto, la prensa se ganó su mote de "cuarto poder", debido a su poder en la opinión pública, la cual se define, siguiendo a Jürgen Habermas, como aquella que se relaciona con el poder y el surgimiento de una democracia ilustrada, a su vez que sufre cambios en su interacción comunicativa y discursiva. ${ }^{4}$

Durante la Revolución mexicana la prensa sufrió diversos cambios que modificaron su estructura interna. Con la irrupción que trajo consigo la Revolución, se marcan dos puntos importantes: 1) la prensa adquirió libertad de opinión como consecuencia de la debilidad en la que cayó el Estado, razón por la cual no pudo controlar la información; y 2) la prensa se robusteció, se hizo un grupo elitista y de poder y, en los años posteriores, se convirtió en un grupo capaz de legitimar o descalificar ante la opinión pública a los actores de distintos grupos políticos. ${ }^{5}$

La fundación de El Imparcial, por Jesús Reyes Espíndola, en el año de 1896, marcó la entrada del periodismo moderno en México. ${ }^{6}$ En este mismo año se dejaron de publicar varios periódicos, como El siglo XIX y El Monitor Republicano, publicaciones que eran representantes de un periodismo pre-moderno en la historia de México. El Imparcial

4 En este artículo se hace uso de la definición de opinión pública que ha elaborado el teórico alemán Habermas, la cual continúa definiendo como: "el espacio público donde se puede construir algo así como opinión pública. La entrada está fundamentalmente abierta a todos los ciudadanos. En cada conversación en la que los individuos privados se reúnen como público se constituye una porción de espacio público [...]. Los ciudadanos se comportan como público, cuando se reúnen y conciertan libremente su opinión, sobre las oportunidades de actuar según intereses generales. En los casos de un público amplio esta comunicación requiere medios precisos de transferencia e influencia: periódicos y revistas [.. .]" Habermas, Jürgen, Historia y crítica de la opinión pública. La transformación estructural de la vida pública, México y Barcelona, Editorial Gustavo Gili, 1990, p. 123; Boladeras Cucurella, Margarita, "La opinión pública en Habermas", Análisis, Barcelona, Universitat de Barcelona, núm. 26, 2001, p. 53.

5 Matute, "Prensa, sociedad y política...", op. cit., p. 65.

6 Ibid., p. 74. 
tomó mucho del periodismo estadunidense, que era uno de los más avanzados del mundo, al mismo tiempo que se beneficiaba de las agencias periodísticas de ese país. ${ }^{7}$ Pero es a partir de la fundación de El Universal en 1916, que la prensa mexicana ingresó a la vorágine del periodismo industrial. ${ }^{8}$ Con la creación de este diario, la prensa mexicana se vio acelerada en su desarrollo. Es decir, la entrada de la prensa mexicana en la modernidad occidental, supone que:

El periodismo es una actividad radicalmente vinculada a la modernidad. El periodismo puede ser contemplado, simultáneamente como causa y efecto de la sociedad nacida del capitalismo industrial. Causa porque la lucha por la libertad de expresión es uno de los aspectos centrales de los movimientos de emancipación social modernos. Y efecto, en el sentido de que la nueva sociedad necesita de nuevas formas de circulación de la información. ${ }^{9}$

La prensa se configuró como un medio por el cual se transmitían ideas, opiniones y crónicas, a su vez que se instauraba al periodismo nacional industrializado en la dinámica del mercado. Con la aparición de El Universal, comienzan a venderse espacios para publicidad. Los artículos, muchas veces, fueron favores políticos y premios económicos, no sólo para el escritor sino para el periódico en general. Esta dinámica la usó Excélsior. De tal forma que el periodista cumple con una doble función, en un momento es vocero de la opinión pública ${ }^{10}$ y construc-

7 Plata Aguilar, Blanca, "El imparcial: su oficio y su negocio", Revista mexicana de las ciencias sociales, México, UNAM, núm. 109, 1982, p. 81.

8 Una característica que presenta la modernidad de la prensa es la presencia, cada vez mayor, de espacios de noticias en detrimento de las secciones de editoriales y artículos de opinión en los diarios publicados en la transición del siglo XIX al XX. Suárez Escobar, Marcela, "Prensa e imagen. El crimen y su representación en la prensa mexicana a principios del siglo Xx", en García de los Arcos, María Fernanda (coord.), La prensa como fuente para el análisis en las ciencias sociales, México, UAM-I, 2009, pp. 193-194.

9 Gómez Gil Rodríguez-Salas, María Luisa, "Círculos y canales de comunicación en el dominio de la ciencia", Revista Mexicana de Sociología, México, UnAm, vol. 39, núm. 4, oct.-dic. 1997, p. 9.

10 Habermas sustenta que la opinión pública tiene variantes continentales, por lo que ésta no se forma de manera inmediata a la publicación de algún periódico o publicación periódica, ya sea semanario, bisemanario o mensual, sino que espera a un consenso para determinar su orientación ideológica. Es necesario tener en cuenta que lo 
tor de la misma; es un transmisor y hacedor de opinión. Además, en diversas ocasiones, cumple la función de vocero del Estado o de una determinada facción política. Lo que genera problemas en una relación ambigua entre el periodista y el poder político.

Analizar la prensa y la relación que guardó con la Revolución mexicana es una tarea compleja por la gran cantidad de periódicos que aparecieron durante la lucha armada de 1910 a 1920 y la posterior pacificación del país de 1920 a 1940. Bajo esta lógica, en el presente artículo se pretende mostrar la posición política que asumió el periódico Excélsior de octubre de 1919 a septiembre 1920, durante la campaña electoral de Álvaro Obregón a la presidencia. Los periódicos habían jugado un papel fundamental durante la historia de México. Los diferentes episodios de la historia mexicana, desde la Independencia hasta la llegada de Porfirio Díaz al poder, habían sido acompañados por ellos. Sin embargo, no habían sido determinantes en la construcción de la esfera de la opinión pública como lo fueron en la Revolución mexicana. El caso de la campaña electoral de 1919 es una muestra de esa nueva dinámica social que relacionaba a la opinión pública, la libertad de expresión y la difusión del periodismo industrial con fines políticos-electorales.

Álvaro Obregón fue uno de los primeros políticos mexicanos que usó un nuevo tipo de instrumento que se le presentaba ante sus ambiciones políticas, a saber: la prensa industrializada como medio de comunicación masivo. Esta estrategia de propaganda electoral era completamente nueva para los políticos mexicanos, y el que la usó desde su nacimiento industrial fue el último caudillo de la Revolución mexicana. Los principales caudillos revolucionarios se mataban entre ellos para alcanzar el poder, buscando darle a México estabilidad y progreso -siempre tratando de respetar las consignas de los programas originales que habían sido postulados durante la etapa armada de la Revolución. Mientras esto ocurría, diversas noticias, en diferentes diarios capitalinos, eran las que ocupaban páginas enteras o columnas breves; las noticias sobre la vida cotidiana de la sociedad capitalina también hacían su aparición en las páginas de los diarios.

que él denomina la tradición latina, es decir, el caso francés, para él se convirtió en algo modélico para América Latina, que a su vez entró tarde en la modernidad y, por ende, la opinión pública fue algo que tardó en consolidarse en esta región del mundo. Habermas, op. cit., pp. 124-135. 
En otras palabras, nada mejor que los periódicos para conocer la realidad de una época.

El espacio del que se hace uso para darle diacronía al tema es la Ciudad de México, porque es el lugar que mayor número de diarios tuvo durante el siglo XIX y hasta bien entrado el siglo XX. Además de que fue el lugar que albergó a los dos principales diarios industriales de la época: Excélsior y El Universal.

EXCÉLSIOR Y LA REBELIÓN DE AGUA PRIETA, 1919-1920

Excélsior no dedicó, en la mayoría de los casos, primeras planas y encabezados a los eventos ocurridos durante la campaña electoral de 1919-1920; sólo cuando éstos se fueron acercando y transformando en disputas álgidas entre los candidatos, el diario comenzó a otorgar dichos encabezados y primeras páginas a la disputa electoral. Habitualmente, estos espacios eran reservados para noticias internacionales, como las consecuencias de la Primera Guerra Mundial; las negociaciones de Estados Unidos con Italia por la región de Fiume; el peligro de la desestabilización balcánica; la situación económica, política y social francesa; la aún y cada vez más tambaleante supremacía británica en el mundo; los acuerdos de paz con Alemania y Austria; y la desmembración del Imperio Otomano.

Una noticia que ocupó los encabezados, por la importancia que tenía en la seguridad nacional, fue la tensa relación que se tenía con los Estados Unidos. Sobre todo, las noticias referentes a la cuestión petrolera, la no intromisión de éstos en los asuntos internos del país y la búsqueda de independencia económica de México. Durante mucho tiempo, aún durante la campaña electoral y la rebelión de Agua Prieta, estos tópicos fueron los que ocuparon principalmente los espacios en las primeras planas de Excélsior.

La campaña obregonista puede dividirse en tres etapas: 1) la que va de la invitación de Carranza a no hacer campaña presidencial -y el pronunciamiento del Manifiesto a la Nación por parte de Obregón, donde se postuló como candidato en 1919- al plan de Agua Prieta; en esta etapa también podemos incluir a los otros dos aspirantes presidenciales: Pablo González e Ignacio Bonillas. 2) La que deviene del susodicho plan de Agua Prieta hasta la muerte de Carranza. 3) La continuación de la campaña hasta la realización de los comicios electorales. Estas 
elecciones se llevaron a cabo ya sin Bonillas y González de por medio, debido a que el primero había perdido a Carranza como su principal aliado político y el segundo había perdido su poder militar. Ambas fueron consecuencias directas de la rebelión de Agua Prieta.

En el caso de Excélsior, se nota esta división en la coyuntura de la campaña electoral de 1919-1920. Las editoriales y opiniones fueron duras y críticas por igual, no escatimaron en cuanto a los adjetivos que se ocuparon hacia los personajes, los cuales fueron desde "oportunistas" hasta "militares rapaces", pasando por "demagogos". Ninguno se salvó. Venustiano Carranza, Pablo González y Rafael Cabrera son los que se llevaron las editoriales y columnas de opinión, que mayor número de calificativos despectivos profirieron. Mientras tanto, en las mismas páginas Obregón y Bonillas fueron menos atacados. Esta postura de Excélsior mostró que las noticias en torno a la Revolución y su discurso ya tenían agotado al país en muchos rubros, como el económico, el político y el social. Las editoriales y las secciones de opinión muestran, de manera constante, lo desacreditado que estaba el discurso de los militares revolucionarios.

Del Manifiesto a la Nación al Plan de Agua Prieta:

EXCÉLSIOR Y LOS CANDIDATOS

\section{Álvaro Obregón}

Para el año de 1919, Obregón ya no estaba en el gobierno, había dejado el cargo de secretario de Guerra y Marina el 30 de abril de 1917, después de esta fecha se había dedicado a la vida privada en su hacienda para practicar la agricultura. A pesar de ello, no había dejado de estar en la vida política nacional y el primero de junio de 1919 lanzó su Manifiesto a la Nación, ${ }^{11}$ en el que se postulaba como candidato a la presidencia de la República, la cual hizo efectiva hasta el mes de octubre del mismo año.

11 Obregón, Álvaro, "Manifiesto a la Nación (1 de junio de 1919)", en Iglesias González, Román (introducción y recopilación), Planes políticos, proclamas, manifiestos y otros documentos de la Independencia al México moderno, 1812-1940, México, UNAM, 1998, pp. 833- 835; Obregón, Álvaro, Ocho mil kilómetros de campaña, México, Fondo de Cultura Económica, 1973, pp. 513-586.

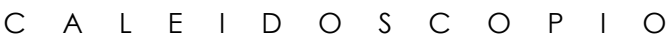


En dicho manifiesto, el general menciona que numerosos grupos de personas le habían enviado cartas para hacerle saber su preocupación sobre qué haría en la vida política del país. Le pedían que se postulara para presidente en nombre de la nación, de la revolución y de la democracia. En su faceta de general, Álvaro Obregón contaba con una gran aureola en cuanto a sus triunfos militares sobre Victoriano Huerta y Francisco Villa, y les supo sacar provecho. No solamente era popular entre los militares, sino que lo era entre los trabajadores, los campesinos y los obreros. ${ }^{12}$

Obregón contaba con grandes cantidades de suscripciones en el periódico Excélsior ${ }^{13}$ y otros periódicos tanto de la Ciudad de México, como de otros estados del país, para hacer que se hablara bien de él. Periódicos como El Heraldo, El Monitor Republicano, La Prensa y el mismo El Universal también se vieron beneficiados por lo apoyos económicos que otorgó Obregón. ${ }^{14}$ Los "apoyos" fueron siempre en diversos rubros, aunque permanentemente con la idea de granjearse artículos de opinión y editoriales que dieran un juicio favorable, a su persona y su causa, por parte de todos ellos. La compra de espacios para publicidad y de suscripciones, las cuales fueron muy generosas, ya que hubo periódicos en el que éstas llegaron a ser de hasta 500 periódicos diarios, ${ }^{15}$ fueron esenciales para la supervivencia de los diarios.

Tal era la imagen que Obregón logró proyectar en los periódicos que después de la muerte de Zapata, donde Pablo González (que se perfilaba como el otro gran candidato a la presidencia y principal enemigo de Obregón en la carrera presidencial) figuró como el principal artífice, el general Benjamín Hill, asesor de campaña de Obregón, sabedor de la posición de éste en los periódicos, se atrevió a realizar un análisis de la situación en abril de 1919, antes de que Obregón comenzara su campaña formal e inclusive antes de que lanzara su famoso Manifiesto, al decir con una precisión estadística difícil para la época:

Entre los periódicos serios se ha incrustado en la conciencia pública en artículos calurosos como un ascua, el diarios [sic] ABC, que es amigo nues-

12 Castro, Pedro, Álvaro Obregón, México, Era-ConaculTA, 2009, p. 15.

13 Serna, Ana María, "Periodismo, Estado y opinión pública en los inicios de los años veinte (1919-1924)", Secuencia, México, Instituto Mora, mayo-agosto de 2007, p. 70.

14 Ibid., pp. 74-77.

15 Ibid., p. 79. 
tro, como en su oportunidad les hice saber. En consecuencia, si antes de la hazaña de Chinameca, don Pablo González tenía siquiera 15\% de probabilidad a su favor, este $15 \%$ se ha reducido a cuando menos, a $5 \%[\ldots]^{16}$

Hill tenía claro que Obregón era el candidato más fuerte. El hombre idóneo para ganar la presidencia. No obstante, con el tiempo y las estratagemas utilizadas por Obregón y su equipo de campaña, la relación con El Universal y Excélsior se fueron enfriando, de tal manera que Obregón y sus partidarios prefirieron alentar al Monitor Republicano, publicación que formaba parte del Partido Liberal Constitucionalista (PLC) y, por lo tanto, apoyaba la candidatura de Obregón. Esta circunstancia, con el paso de los días, le fue adversa, ya que Excélsior, de manera gradual, fue criticando al candidato y su postulación.

No obstante esta dinámica de Excélsior, Obregón siguió con las suscripciones y espacios pagados, razón por la cual el candidato más atacado en el diario era Pablo González. Hay que recordar que tanto Excélsior como El Universal estuvieron en una campaña a favor del civilismo y al ser González un militar en activo, ocuparon esa condición para elaborar una campaña de desprestigio hacia él.

Una de las primeras opiniones que hizo el periódico, no sólo contra González sino contra todo el carrancismo, fue en el contexto de una entrevista hecha a Rafael Cabrera, ideólogo del régimen carrancista. En dicha entrevista, Cabrera, con palabras elocuentes, puso en entredicho la realización de los plebiscitos, argumentando la falta de condiciones reales para que éstos pudieran llevarse a cabo debido, según el secretario de Hacienda, a los grandes problemas que aún tenía el país y su pacificación. ${ }^{17}$

Estas declaraciones se dieron en un contexto donde en la opinión pública se manejaba, desde tiempo atrás, que Carranza no pretendía dejar el poder, sino más bien buscar reformar la Constitución y ser reelecto, posibilidad lanzada por Cabrera, argumentando el clima de violencia y fragmentación que era patente en el país. Esta opción resultaba desagradable para todas las facciones revolucionarias en México. Excélsior, con motivo de las declaraciones hechas por Luis

16 Benjamín Hill a Álvaro Obregón, 20 de abril de 1919 en ACT, fondo 11, serie 020700, expediente H- 5/138, inv. 886.

17 Excélsior, México, D.F., 30 de junio 1919; Obregón, Ocho mil kilómetros de campaña... op. cit., pp. 551-583. 
Cabrera, realizó encuestas entre la gente del ámbito político. Destaca la realizada al miembro del Congreso de la Unión, Alfonso Rodríguez Miramón, quien propuso, para solucionar la situación de crisis, crear la vicepresidencia de la República. ${ }^{18}$

Obregón se postulaba como candidato pero, sobre todo, como un salvador de los ideales de la Revolución que, según él, Carranza había traicionado con su intento de perpetuarse en el poder mediante Ignacio Bonillas. En su Manifiesto de 1919 planteaba que el orden constitucional devuelto a la nación había sido corrompido por el presidente y sus ansias de continuar en el poder, y sólo él podía rescatarlo. ${ }^{19}$ El periódico, en su afán de dar una imagen de neutralidad y objetividad, se dio a la tarea de entrevistar a diputados que simpatizaban con el obregonismo; por ejemplo, la opinión de Manuel Chávez, que dijo que a su parecer "el señor candidato Obregón había procedido cuerdamente al definir su actitud. Ya que la opinión pública así se lo demandaba" ${ }^{20}$ También publicó la opinión de los diputados Daniel Sánchez, Benjamín Balderas y Francisco Arreola, las cuales estaban en el mismo sentido. Excélsior dio espacio para los comentarios que no eran favorables hacia Obregón, como el de Antonio Villalobos que dijo que "era prematura y debía haber esperado". ${ }^{21}$ De esta forma, buscó mostrar su imparcialidad en la emisión de noticias.

Excélsior cuestionó la postura del candidato y su Manifiesto, que era, según el editorialista, el documento que mejor enumeraba los problemas nacionales, pero no lograba darle solución a los problemas que atravesaba la nación. ${ }^{22}$ La crítica se expandió no sólo a Obregón, sino en general a la vida política de México y su inexistente democracia, al decir: "si fuésemos verdaderamente demócratas la dificultad para una transición de poder no existiría, como no existe en las verdaderas democracias. En éstas el que pierde [...] respeta al triunfador y aplaza sus reivindicaciones para la próxima campaña electoral $|\ldots|$ sin suscitar revoluciones". ${ }^{23}$

18 Excélsior, México, D.F., 29 de junio de 1919.

19 Obregón, "Manifiesto a la Nación...", op. cit., p. 832.

20 Excélsior, México, D.F., 6 de junio de 1919.

21 Idem.

22 Excélsior, México, D.F., 9 de junio de 1919.

23 Excélsior, México, D.F., 19 de junio de 1919. 
La historia en su versión Magistra Vitae ${ }^{24}$ mostraba que éste era el recurso utilizado por los políticos-militares mexicanos que buscaban acceder al poder. Los eventos hacían ver que ésta era una solución factible. Por su parte, Obregón, que se presentaba a sí mismo como el salvador de la Revolución, era cuestionado por la editorial del diario al opinar que había dicho casi sin ambages ni reticencias: "EL REMEDIO SOY YO, solución que podría ser la aceptada [... pero que está envuelta en un incierto futuro $[\ldots]$ conjurando si es vencido $[\ldots]$ no se resigne a su derrota". ${ }^{25} \mathrm{El}$ diario no presentaba un panorama alentador sobre la postulación obregonista. A la postulación del "Manco de Celaya" se le cuestionaba su mesianismo revolucionario que él, tan petulantemente, se adjudicaba.

Obregón, en su Manifiesto, había hecho saber que no necesitaba de partidos políticos que lo respaldaran en su aventura hacia la presidencia, dado que él era el defensor, lógico e idóneo de los preceptos revolucionarios. Una de las razones de mayor peso político que expuso fue que no había ningún partido político que fuera liberal, sino que todas las organizaciones que le habían brindado su apoyo hacia la presidencia apenas podían denominarse facciones, y dejar su candidatura en manos de alguna de éstas era provocar una división entre los revolucionarios. ${ }^{26}$ A pesar de esta situación, en la búsqueda de una mejor plataforma política que le diera solidez a su campaña, abrazó la bandera del Partido Revolucionario Sonorense (PRS) y, con el paso de los días dejó que el PLC también lo nombrara su candidato.

La crítica mordaz que comenzó a realizar Excélsior en sus páginas de editoriales y crónicas mostró el desconocimiento de la historia mexicana y el escaso programa político que el candidato Obregón enunciaba hacia la nación. ${ }^{27}$ El caudillo sonorense creyó ser el candidato natural, por lo que el diario Excélsior habló de él como un nuevo Napoleón, y nos decía que su postura de caudillo era la negación de la libertad y sólo confirmaba: "iqué lejos estamos de la democracia!". ${ }^{28}$

24 Koselleck, Reinhart, "Historia Magistra Vitae", en Futuro pasado. Para una semántica de los tiempos históricos, Madrid, Paidós, 1993, pp. 43-45.

25 Excélsior, México, D.F., 19 de junio de 1919.

26 Matute, Álvaro, Contraespionaje político y sucesión presidencial, México, UNAM, 1985, p. 37.

27 Id. y la publicación realizada en Excélsior, México, D.F., 7 de junio de 1919.

28 Excélsior, México, D.F., 9 de junio de 1919. 
La constante correspondencia que se enviaron entre sí Obregón y González, hace pensar que la prensa llegaría a tener páginas llenas de debate entre estos personajes. Sin embargo, el periódico descalificó el modo tan pueril en que manejaron esta situación los dos candidatos. ${ }^{29}$ Obregón, por un lado, se dedicó a evadir de manera constante y con respuestas muy diplomáticas las acusaciones que elaboró el general Pablo González (véase Imagen 1). Con el transcurso de los días, se puede observar que Excélsior, que al principio colocaba las acusaciones en primera plana, no tardó en enviarlas a las páginas interiores.

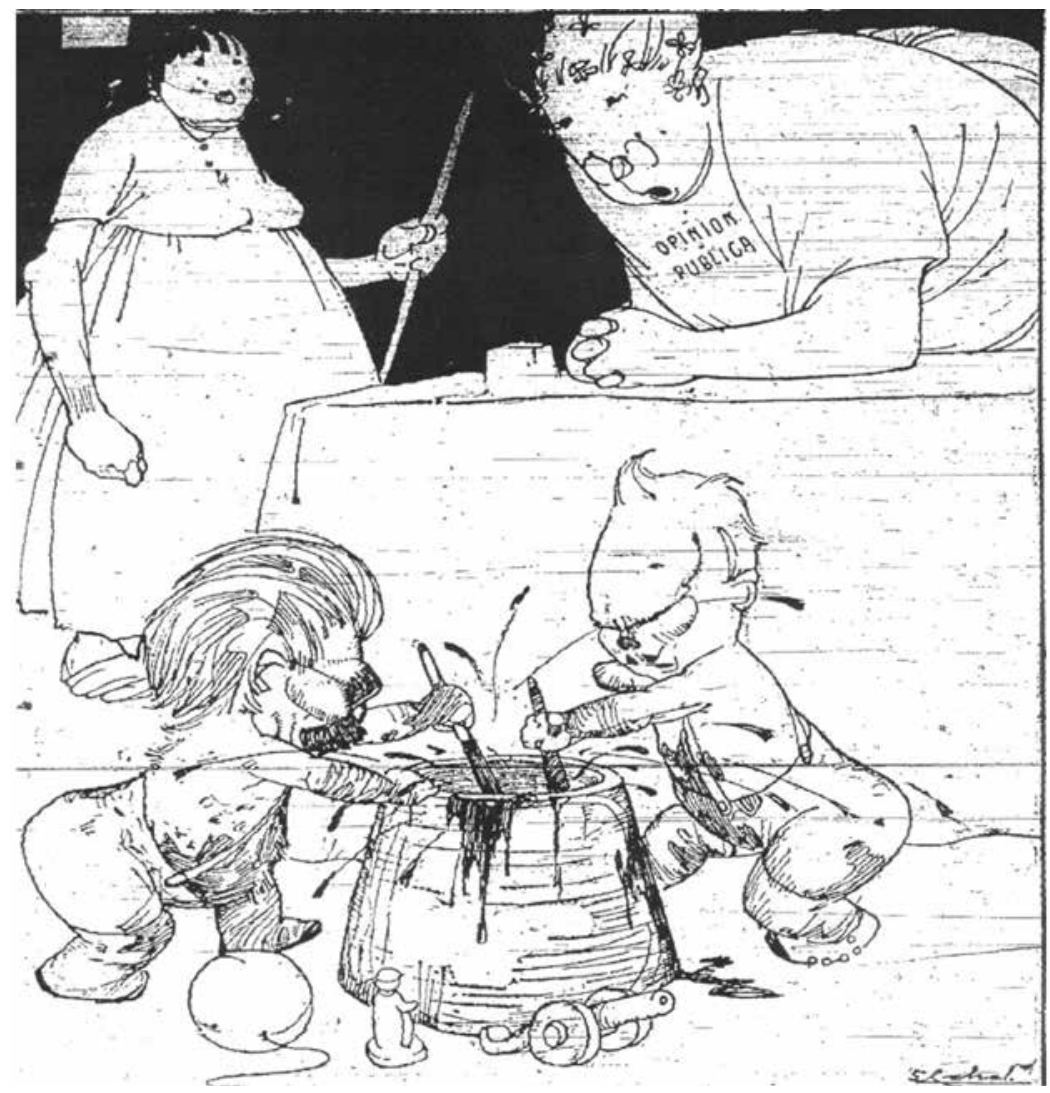

Ilustración 1. Caricaturas de Excélsior, México, D.F., 29 de julio de 1919.

29 Excélsior, México, D.F., 16 de octubre de 1919. 
Con el advenimiento de los sucesos acecidos en la rebelión de Agua Prieta, Obregón postergó su campaña hasta terminar el conflicto armado y todo el cabildeo político que ésta acarreó. Por lo tanto, su campaña prosiguió hasta el 3 de julio de 1920, fecha en que se le licenció nuevamente del ejército; esto dio pauta a que la campaña hacia la presidencia siguiera en paz. Claro es que Obregón ya no encontró enemigos políticos que pusieran en tela de juicio su objetivo de obtener la presidencia.

\section{Pablo González}

No todo fue un ataque directo y frontal contra Obregón en su campaña. Excélsior, sabedor del costo político que esto le podía acarrear en caso de que Obregón ganará la presidencia en las elecciones, balanceó sus comentarios; de tal manera que se hiciera sentir un antimilitarismo en vez de una postura antiobregonista. Bajo esta lógica, los comentarios no sólo eran contra Obregón, sino también contra el general neoleonés, Pablo González, las cuales, inclusive, fueron más mordaces.

La campaña de González avanzaba lentamente, por lo cual, en su editorial del 26 de junio de 1919, Excélsior no dudó en decir que González, en primer lugar, tardó para definir su postura sobre si participaría o no en los comicios de 1920; en segundo lugar, actuó con lentitud e indefinición para comenzar su campaña; y en tercer lugar, escribió constantes cartas dirigidas a Obregón y publicadas en la prensa para hacer, según él, acuerdos en los que se respetaran los resultados de los plebiscitos electorales. ${ }^{30}$ Excélsior argumentó que la actitud de González mostraba debilidad política.

La actitud de González irritó constantemente a la prensa. La baja que solicitó del ejército para poder dedicarse a su campaña fue una de las tantas veces que tuvo fricciones con ella. Los pretextos para llevar a cabo su baja del ejército fueron tan diferentes que la prensa dudó de este acto. ${ }^{31}$ De forma poco brillante, el general de división del constitucionalismo inició su campaña, de manera oficial, el día 8 de noviem-

30 Excélsior, México, D.F., 24 de julio de 1919.

31 González, viendo los problemas sobre la soberanía en Sonora que confrontó a la federación y al estado, dijo que él prestaría servicios si no se lo impidiera su calidad de candidato presidencial. Excélsior, México, D.F., 13 de enero de 1920. 
bre de 1919. Antes de esta fecha, González se había postulado, pero no había iniciado campaña, sólo había realizado manifiestos. González dijo que la carta para su retiro del ejército la mandó directamente al presidente de la República, Venustiano Carranza, haciéndole saber que su candidatura era algo primordial para la democracia de la nación. ${ }^{32}$

Sin embargo, González había cuidado los detalles más ortodoxos que se necesitaban para una campaña, la formalidad de los tiempos, su baja del ejército y su postulación por parte de un partido político, como lo era la Liga Democrática (LD), la cual crearía las bases para su campaña. Pablo González, a diferencia de Obregón y Bonillas, había sido electo de entre varios precandidatos del LD. Su propaganda fue la más completa, aunque Excélsior no lo viera así e, incluso, lo acusara de un personaje viejo y ajeno a los tiempos que vivía el país. ${ }^{33}$ Sus manifiestos, panfletos y artículos, dirigidos hacia los medios urbanos de la capital y otras regiones del país, mostraron que tuvo mayor arraigo en la capital que en el interior de la República. El juego de intereses políticos se debió a que González no tuvo una buena imagen y percepción en Excélsior y en otros diarios. Esto se puede explicar debido a que González no tenía suscripciones o cualquier otro "apoyo" en los periódicos, y además era militar, algo anacrónico para la democracia, según los diversos diarios de la capital.

Ya con dos candidatos en contienda, el caso Obregón-González, la opinión pública se comenzaba a exaltar en los diarios de gran circulación de la Ciudad de México. Las cartas que se publicaron del diálogo entre los dos generales sacaron a la luz constantes acusaciones que se hacían entre ellos. Las temáticas eran variadas: acusaciones de poder excesivo en el ejército, que si alguno de ellos era más revolucionario, sus vinculaciones con la élite porfirista o sus nexos con grupos rebeldes.

Otra manera en que el periódico hizo sentir su opinión fue mediante la caricatura política. La caricatura que se utilizó en contra de los candidatos militares hace ver que la percepción que se tenía en la opinión pública sobre los dos aspirantes presidenciales era, en términos generales, mala. Se les veía como dos personajes poco comprometidos con la población y solamente interesados en el poder; y poco atentos a las ideas que la opinión pública se hiciera de ellos (véase Ilustración 2).

32 Excélsior, México, D.F., 3 de enero 1920.

33 Excélsior, México, D.F., 4 febrero de 1920. 


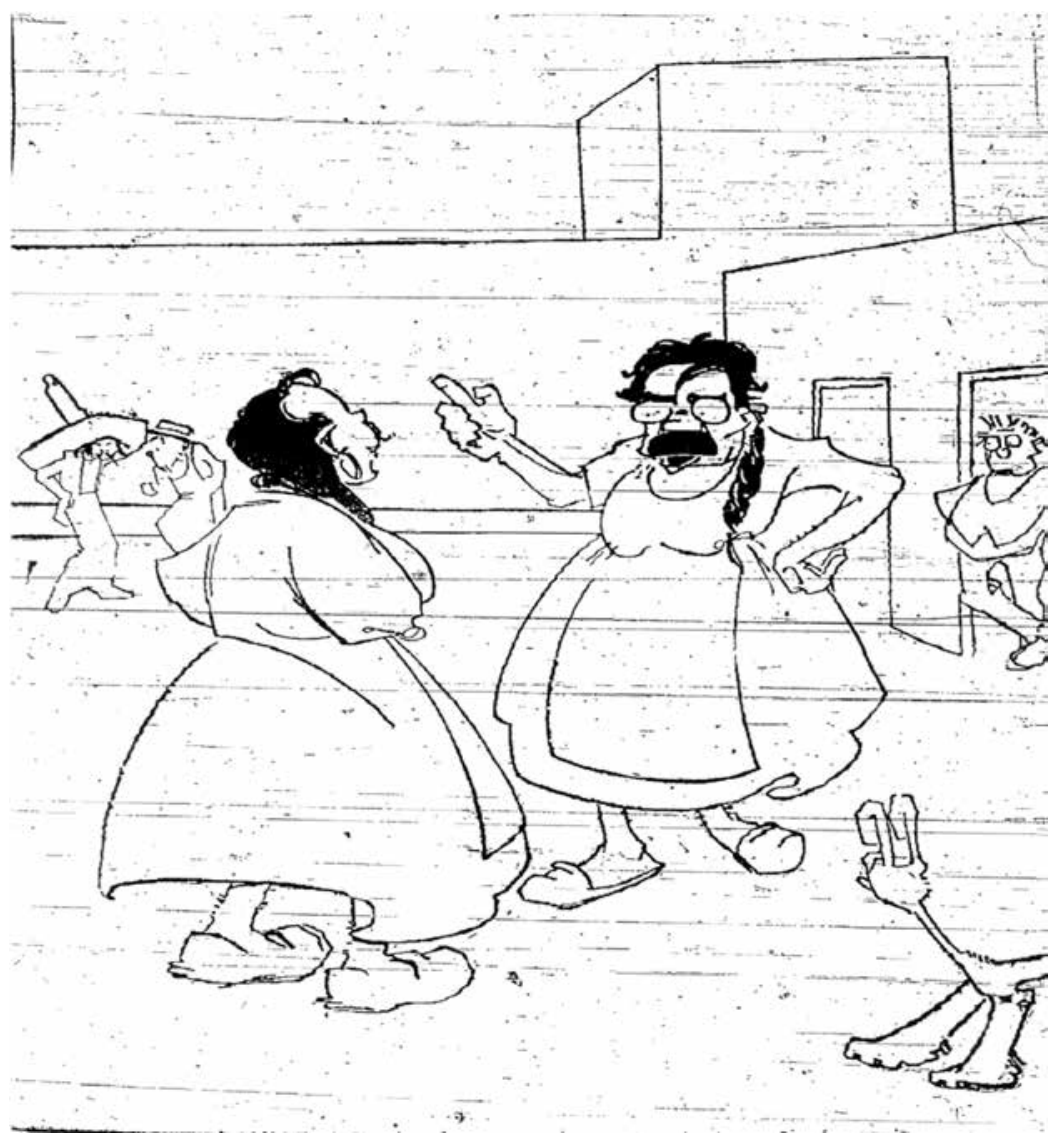

Ilustración 2. "Cuando las comadres hablan las verdades salen". Excélsior, México, D.F., 13 de noviembre de 1919.

La lucha entre los candidatos mostró, según Excélsior, "el deseo de cada uno $[\ldots \mid$ por ser el ungido del sufragio, invocando su prestigio $[\ldots]$ sus limpios antecedentes [...] el uno (Obregón) conservando, el otro (González) sacando su espada de breno de su cuerpo de ejército en la mano". ${ }^{34}$ Mediante esta opinión recogida en Excélsior, se puede observar que la reputación que tenían los candidatos en la opinión pública era

34 Excélsior, México, D.F., 26 de junio de 1919. 
mala. No sólo por ser militares, sino, según la prensa, "por su ambición de poder desmedida poniendo en vilo nuevamente la frágil vida democrática que se buscaba imponer en el país. A ambos les importaba poco la vía para alcanzar el poder, y eso la prensa lo sabía". ${ }^{35}$

La campaña de González fue la que contó con menos apoyo dentro de la prensa. Su amplio programa, el cual contenía las acciones que iba a realizar dentro de la Revolución, incluía:

La pacificación y el restablecimiento del orden en todo el territorio nacional, no sólo por medios de violencia, sino también y muy principalmente, por medios de convencimiento y de atracción; la disminución paulatina del ejército permanente, su organización y moralización para que con menos costo resulte más respetable y eficiente; el establecimiento de la guardia civil para la eficaz persecución del bandolerismo; la libertad de enseñanza como principio y la protección a la educación pública, creando un departamento especial para atenderla; la solución de las cuestiones obreras y agraria a base de equidad y sin lesionar derechos legítimamente adquiridos; la dignificación del empleado público por medio de una ley del servicio civil que sustraiga de las veleidades políticas a los servidores de la nación y les garantice la permanencia en sus puestos, a base de aptitud únicamente; la pureza del manejo de los fondos públicos y la reorganización de nuestro sistema financiero con orientaciones definidas y por elementos competentes en la materia; la administración expedita de justicia, expurgando nuestra legislación de las trabas que la hacen lenta y costosa, y la dignificación de los miembros del poder judicial; la responsabilidad efectiva de los altos funcionarios del poder ejecutivo; la autonomía del municipio; la libertad de conciencia plenamente garantizada; la creación del fundo patrimonial; la definición de nuestra política internacional, en términos decorosos y convenientes para los intereses de nuestro país. ${ }^{36}$

Esta extensa cita muestra las razones por la cuales Excélsior, en su sección de editorial, se muestra poco receptivo a esta postura ideológica a la que llamó retrógrada y poco creíble. El programa es un tanto extenso en sí y para Excélsior ratifica "su convencimiento de que no hay programa malo como no hay uno que se cumpla en la historia

35 Excélsior, México, D.F., 30 de noviembre 1919.

36 Excélsior, México, D.F., 21 de enero de 1920. 
de México", ${ }^{37}$ menos proviniendo de un militar, por lo que el propio periódico lo condena: "ese programa es el más contradictorio y condenatorio del que la última revolución al día siguiente del triunfo ha pretendido fundar en preceptos legales. Basta fijarse en él con algún detenimiento". ${ }^{38}$ Pero a pesar de todo lo dicho por el diario, el general González contaba con un aparato, una programática de campaña, en la que había hecho uso de la retórica e intereses políticos que ninguno de los otros dos candidatos había tomado en cuenta. Se puede inferir, de este choque con la prensa, que Pablo González no pudo y no supo ganarse a la prensa para lograr que su candidatura y su programa no fueran denostados públicamente.

En la rebelión de Agua Prieta, González jugó un papel fundamental al retirar sus facciones militares de la capital, pero dejó desprotegido a Carranza para que éste sucumbiera ante el movimiento dirigido por Adolfo de la Huerta. González pensó que el movimiento le acarrearía beneficios ${ }^{39}$ No obstante, el triunfo sonorense y las jugadas políticas de los obregonistas lo dejaron fuera de la contienda por la presidencia. Una campaña que nunca pudo asirse del apoyo suficiente ni entre la población y mucho menos en la prensa de la Ciudad de México.

\section{Ignacio Bonillas}

Cuando Carranza dijo que el mejor candidato para sucederlo en la presidencia era un civil, y este era Ignacio Bonillas, todo el mundo, incluido la prensa de la Ciudad de México, vio esto como una imposición por parte de su gobierno. Ignacio Bonillas había sido revolucionario. No obstante, para su desgracia sólo había estado en el país durante el movimiento de Madero. Por lo tanto, se había perdido gran parte del conflicto en su fase armada y no vio el triunfo constitucionalista. Estos hechos jugaron en su contra. Se le acusó de ser poco revolucionario, a

37 Excélsior, México, D.F., 21 de enero de 1920.

38 Excélsior, México, D.F., 21 de enero de 1920.

39 La indisciplina fue una constante en el ejército de Carranza desde que era el ejército constitucionalista. A partir que derrotó al entonces ejército federal y la escisión de sus aliados, villistas y zapatistas, el desprestigio persiguió a este grupo del ejército y Pablo González contribuyó a ello. Véase Garciadiego Datan, Javier, "La Política militar del presidente Carranza", en Hernández, Alicia y Manuel Miño Grijalva (coords.), Cincuenta años de historia de México, vol. 2, México, El Colegio de México, 1991, pp. 437-470. 
tal grado que se le pusieron apodos como "Mr. Bonillas" o "Flor de té" para desprestigiarlo ante los militares, los cuales eran el grupo más amplio y el que iba a decidir las elecciones.

El 19 de febrero de 1919, la llegada de Bonillas al país, procedente de Estados Unidos, para su campaña presidencial se consideró todo un suceso. A su llegada, el candidato leyó un extenso documento donde aceptaba la candidatura formalmente y, desde ese momento, fue el candidato civilista apoyado por Carranza. La formación de convenciones a favor de este candidato fue una constante, la primera de ellas se llevó a cabo el día 20 de febrero de 1920, auspiciada por el Partido Nacional Democrático (PND). Esta convocatoria que expidió el partido decía: "dirigiéndose hacia los partidos políticos de la nación: se convoca a todos los partidos políticos de la república mexicana que postulen o hayan postulado al ingeniero Ignacio Bonillas como candidato a la presidencia de la república en las próximas elecciones para que concurran a una asamblea general que tendrá verificativo en la ciudad de México" ${ }^{40}$ La idea de que un civil fuera el sucesor de Carranza era apoyada por un sector de la opinión pública, aun cuando había algunos que pensaban que al seleccionar a Bonillas, Carranza dominaría el escenario político mexicano. Oficialmente, Bonillas fue presentado como candidato por el Partido Liberal Democrático (PLD), al finalizar el año 1919; y al iniciarse el año de 1920, fue organizado el Partido Civilista (PC) para trabajar por su elección.

En tanto, Bonillas, con la ayuda de los generales Aguilar y Barragán, proclamaba las virtudes del civilismo. Los enemigos políticos del candidato se referían a él como "Míster Bonillas" y exponían que su elección equivaldría a una imposición, dada la ayuda que recibía de Carranza. Excélsior y los periódicos de la Ciudad de México, a pesar de que abogaron y apoyaron al civilismo, se mostraron escépticos sobre la candidatura de Bonillas. Los periódicos lo consideraron una candidatura forzada; sin embargo, como el civilismo era parte de sus ideales que manejaron, tuvieron a bien apoyarlo y se demuestra en los extensos números de páginas que le dedicaron a su llegada. Sobre todo, cuando el mismo presidente Carranza se presentó en una recepción para apoyarlo. ${ }^{41}$ A pesar de este apoyo, a Bonillas no le dio tiempo de hacer una campaña que pudiera haberlo hecho un candidato fuerte, esto se

40 Excélsior, México, D.F., 17 de enero de 1920.

41 Excélsior, México, D.F., 14 de marzo de 1920. 
debió a la rebelión de Agua Prieta. Después de ésta, desapareció del mapa político mexicano.

\section{Del Plan de Agua Prieta A la CAMPaña}

El Plan de Agua Prieta fue el que configuró un modelo político que el país no conocía hasta ese momento. La hegemonía sonorense se asomaba a la historia política del país. El triángulo que conformaron Obregón, Calles y De la Huerta tenía una forma diferente de ver la política revolucionaria, por lo cual es importante dimensionar la revuelta de Agua Prieta como uno de los acontecimientos más importantes del país. ${ }^{42}$

El 11 de abril de 1920, en vísperas de las elecciones, el candidato Álvaro Obregón fue llamado a comparecer en el juicio del general Roberto Cejudo. Acompañado de Hill, Rafael Zubarán y Miguel Alessio Robles, y seguido de una masa de partidarios, Obregón entró al salón del consejo de guerra de la prisión de Santiago Tlatelolco, con el propósito de enfrentarse a la acusación que había formulado Juan Barragán. La acusación consistía en una correspondencia dirigida por el señor Cejudo a Obregón y, por la cual, finalmente se dictó proceder en contra de los acusados ${ }^{43}$ por el delito de sedición, previsto y penado en el artículo 315 de la Ley Penal Militar -designando al Licenciado Pascual Morales Molina, Juez Instructor Especial Militar, para que bajo su dirección se iniciara el procedimiento penal respectivo. De esta manera, el entonces presidente Carranza pretendió haber eliminado a Obregón de la carrera presidencial, mientras declaraba en el diario La Prensa:

Yo nunca he hecho uso de los medios que el ciudadano Obregón ha aplicado para llegar con su ambición al poder. Esos medios, como es bien sabido, consisten en haberse involucrado en la rebelión, preparándola de antemano en el proceso del llamado general Cejudo; unido a bandidos como Genovevo de la O y otros, como se demuestra también con las cartas

42 La llegada de los sonorenses al poder se puede calificar del caudillismo electoral a la creación del PNR en 1929. Meyer, Jean, "El caudillismo electoral hasta 1929", en Medina Peña, Luis, El siglo del sufragio. De la reelección a la alternancia, México, Fondo de Cultura Económica-CONACYT, 2010, pp. 81- 114.

43 Excélsior, México, D.F., 28 de abril de 1920. 
recogidas y suscritas por el general Benjamín G. Hill. El procedimiento, no es honrado, como no lo es tampoco el ciudadano Obregón [....$^{44}$

Al dirigirse a Obregón como ciudadano y no con el título de general, Carranza se mostraba molesto; consideraba al general como enemigo de su gobierno porque no estaba con él, y no había más que un dilema: atacarlo o sostenerlo, declaraba que "hasta ese momento no había tratado de limitar la participación de ningún candidato, pero ahora estaba resuelto a defender la entrada a la presidencia de Obregón, porque ha demostrado carecer de aptitudes" ${ }^{45}$ En este contexto, la opinión pública fue retirando su apoyo a Carranza. En toda la prensa, el juicio en el que se vio envuelto Álvaro Obregón se concibió como una manipulación del sistema legal por parte de Carranza para quitarlo del camino a la presidencia.

La estancia de Obregón en la Ciudad de México resultó contraproducente para el gobierno, pues llegó a un entendimiento con Pablo González el 11 de abril de 1920, y a los dos días huyó con ayuda del ferrocarrilero Margarito Ramírez y de algunos zapatistas que lo llevaron hasta Chilpancingo. Al temerse la aprehensión del candidato, se discutió su fuga cuanto antes de la capital de la República. Rendida la declaración del general ante un juez militar, Obregón había sido citado para el siguiente día, por lo cual se resolvió que huyese esa misma noche y de acuerdo con el plan aprobado, subió a un automóvil con Zubarán Campmany, Luis N. Morones y Alessio Robles. Al verlos, la policía, que rodeaba la casa en cuadrillas de varios motociclistas, siguió el automóvil que cruzó varias calles, pero el candidato cambió su ropa por las de sus acompañantes y los agentes que los seguían no se dieron cuenta de tal cambio; mientras tanto, Obregón tomó un auto de alquiler, se dirigió a la colonia Guerrero donde vivía don Margarito Ramírez y huyó.

Cuando la tensión entre el gobierno de Sonora y Carranza llegaba a la mayor algidez, Adolfo de la Huerta se convirtió en abanderado de una rebelión defensiva frente a la ofensiva federal. ${ }^{46}$ La rebelión so-

44 La Prensa, 1943. Citado en Tamayo, Jaime, "Los ejes constitutivos del obregonismo: populismo, jacobinismo, socialismo y bonapartismo", Iztapalapa, México, UAM-I, núm. 32, ene.-jun. de 1994, p. 34

45 Excélsior, México, D.F., 18 de abril 1920.

46 Dulles, John W. F., Ayer en México. Una crónica de la Revolución (1919-1936), México, Fondo de Cultura Económica, 2003, pp. 24-33. 
norense contra Carranza comenzó el mismo día de su huida, mientras Obregón se escondía en la casa del ferrocarrilero Margarito Ramírez. ${ }^{47}$ Para el 15 de abril, la rebelión era respaldada por el gobernador de Zacatecas y Pascual Ortiz Rubio, gobernador de Michoacán, quien era partidario de Obregón por tener algunas diferencias con Carranza.

A lo largo de la historia mexicana, se acompañaron las sublevaciones armadas con planes que intentaban explicar y justificar los acontecimientos. En Sonora se expidió, el 23 de abril de 1920, el Plan de Agua Prieta para justificar el levantamiento contra el orden federal. La proclama de dicho plan se debió al gobernador de Sonora, De la Huerta, y a los generales Plutarco Elías Calles y Salvador Alvarado. El mérito de su redacción corresponde a Gilberto Valenzuela, entonces presidente de la legislatura del estado de Sonora.

El diario Excélsior publicó diversas noticias sobre el problema del estado de Sonora con el gobierno carrancista. En la noticia escrita el día 24 de abril de 1920, que se ubica en la página 3 del periódico como continuación de la página principal, se puede ubicar la importancia que los sucesos iban tomando en los diarios con el pasar de los días. La noticia del rompimiento de Sonora con el pacto federal se manejó en Excélsior como una noticia relevante. Tanto en la editorial como en la noticia de ocho columnas, se puede vislumbrar la importancia que la rebelión iba teniendo. La columna describe el suceso "como muestra de rebeldía del estado de Sonora y muestra de falta de poder por parte del gobierno federal al permitir que los rebeldes de Sonora quebranten el pacto federal" ${ }^{48}$ A partir de ese momento, las pocas noticias de la revuelta se manejaron como noticias de ocho columnas.

En los diarios de gran circulación de la capital de la República, se había puesto en tela de juicio, con miles de ejemplares, el poco apoyo que ya tenía la presidencia de Carranza para ese momento. La debilidad que mostraba el gobierno de Carranza se hace sentir en la opinión pública, al proclamar Excélsior la debilidad del gobierno para defender el pacto federal. En la sección editorial se enuncia una postura interesante que puede tomarse como el preludio de la ruptura entre Excélsior y el régimen de Carranza:

47 Tobler, Hans, La Revolución Mexicana. Transformación social y cambio político, 1876-1940, México, Alianza Editorial, 1994, p. 457.

48 Excélsior, México, D.F., 12 de abril de 1920 
El gobierno que encabeza el señor presidente Carranza ha dado muestras claras de no tener el control del país y lo que en algún momento se mencionó como un objetivo de esta administración acerca de la pacificación de este país hoy suena como un sueño casi inalcanzable. Ayer [se refiere al día 23 de abril de 1920| el gobierno estatal de Sonora, encabezado por el señor De la Huerta ha roto el pacto federal poniendo en peligro la estabilidad económica y política de la nación [... el el gobierno ha mostrado su ineficacia para solucionar este conflicto antes de que sucediese, sin embargo será necesario que el gobierno negocie para solucionar este problema que sólo muestra $[\ldots]$ debilidad e ineficacia del gobierno mexicano. ${ }^{49}$

La columna de opinión de Excélsior muestra que el periódico comenzaba a dejar de apoyar al régimen de Carranza. La crítica de la edición del día 24 de abril es una muestra de que la coyuntura afectaba a los actores políticos y tenía daños colaterales para todos ellos. Carranza comenzó a perder de manera cada vez más clara a sus aliados políticos, entre estos se contaba a Excélsior. Una de las críticas es la añorada pacificación del país, y el Plan de Agua Prieta era una muestra de que el gobierno carrancista había fallado en ese quehacer nacional. Por si esto fuera poco, en esta misma edición, Excélsior, en su editorial, continúa diciendo sobre el gobierno de Carranza:

La debilidad para tener acuerdos sobre el imperio de la ley por parte de Carranza y sus correligionarios, ha puesto en riesgo la seguridad de la nación con el temor de una nueva y muy posible escisión del territorio nacional $[\ldots]$ Por su parte, los Estados Unidos muy rapaces han seguido de cerca el problema y seguramente harán todo lo posible por evitar una posible solución de parte del gobierno mexicano..$^{50}$

La editorial del periódico estaba cansada, y ésta fue un parámetro de la opinión pública capitalina. El problema con el estado de Sonora es una muestra palpable de la preocupación que se hacía sentir en el orden de los intereses mexicanos, donde inclusive una nueva pérdida de territorio resultaría fatal. Todo esto emanaba de los pésimos resultados, según la prensa, que hasta ese entonces había dado el gobierno de Carranza.

49 Excélsior, México, D.F., 24 de abril de 1920

50 Excélsior, México, D.F., 24 de abril de 1920. 
Con respecto al Plan de Agua Prieta, Excélsior tenía una continuidad de perspectiva sobre la postura del estado de Sonora y del gobierno federal. La perspectiva era poco alentadora. Según nuestra percepción, el día 24 de abril de 1920 el gobierno carrancista había perdido definitivamente al periódico Excélsior, ya que los ataques eran cada vez más mordaces y directos. La persona de Carranza fue denostada cada vez más. En este momento, se dio el viraje hacia el oportunismo de Obregón que iba ganando adeptos, según Excélsior: "Obregón tenía todo el derecho para restablecer el programa revolucionario".

El día 24 de abril, el periódico Excélsior se dio cuenta que tenía que romper sus lazos con Carranza de forma tácita. El diario había hecho una lectura de la realidad del escenario político. Este cambio de postura, que si bien no fue radical, se nota en las opiniones o las noticias. Dos aspectos son rescatables en las noticias subsecuentes: el tono fue más afable, por lo cual las críticas fueron menos duras y vieron en el "Manco de Celaya" una opción de que la democracia puede radicar de manera definitiva en México; ${ }^{51}$ y los eventos ocurridos se comenzaron a escribir en un sentir de injusticia hacia Obregón de parte de Carranza. ${ }^{52}$

Durante los días que estaban ocurriendo los sucesos en Tlaxcalantongo, la prensa no colocó los dichos acontecimientos en las primeras páginas. Es interesante acercarse a la prensa en este suceso, no sólo para reconstruirlo -lo cual, sin lugar a dudas, ya de por sí es de un valor inestimable-, sino para analizar y presentar cómo observó la prensa este evento. Excélsior siguió con detalle los eventos que precedieron la muerte de Carranza, la cual lamentaron profundamente..$^{53}$ No obstante, no denunció la muerte del Primer Jefe de la Revolución con ahínco.

La muerte del otrora máximo Jefe de la Revolución no se ganó o se perdió en las hojas y tinta de un periódico, ni siquiera en las líneas escritas por un periodista. Sin embargo, esta serie de vectores ayudaron para hacer que pronto se viera a Carranza como anacrónico y, por lo tanto, exhibir que era necesario dar un paso a un costado para que otro revolucionario tomara el poder. También existió el reclamo de por qué no se eligió un civil para la reconstrucción del país. En este último tibio esfuerzo sobre la posibilidad de que un civil accediera a la presidencia, los periódicos, sobre todo aquellos que fueron adeptos al régimen y al

51 Excélsior, México, D.F., 2 de mayo de 1920

52 Excélsior, México, D.F., 4 de mayo de 1920

53 Excélsior, México, D.F., 20 de mayo de 1920. 
antimilitarismo, como Excélsior y El Universal, mostraron que su postura sobre Obregón no era netamente genuina, sino que sus directores, periodistas y editorialistas sabían el capital político y económico que se jugaban si atacaban a los nuevos detentadores del poder. Los sucesos en Tlaxcalantongo fueron una muestra de la genialidad política en diversos ámbitos en los que se supo mover Obregón. La nula denuncia de la muerte de Carranza es parte de una tendencia que muestra una vez más que la misma opinión pública ya se había agotado de este tipo de situaciones, además de ser algo normal entre revolucionarios. ${ }^{54}$

Obregón había ganado por partida doble, ya que se deshizo de sus dos adversarios más poderosos: Venustiano Carranza y Pablo González. El primero yacía en un lugar frío y oscuro: la tumba. El segundo había perdido su poder político y, principalmente, su poder militar, aunque conservó la vida con la llegada de Adolfo de la Huerta a la presidencia de manera interina. La facción del ejército de González pasó a formar parte del nuevo grupo de poder de los sonorenses. Al final, Pablo González tuvo que salir del país.

Cuando el conflicto terminó y se decretó el triunfo de Obregón, Excélsior sólo avaló la situación. El nuevo régimen estaba por llegar y la coexistencia se había dado. Si bien Excélsior y El Universal eran marcadamente antimilitaristas, éstos tuvieron a bien aprender la lección de periódicos de otros tiempos y espacios geográficos: dejaron de pelear con el nuevo régimen y empezaron a convivir con él.

Ahora Obregón se enfrentaba a un problema que supo sortear de buena manera: el legitimarse políticamente después de su movimiento de Agua Prieta para acceder a la presidencia, y para esto usó un mecanismo que ya estaba utilizando: su campaña electoral, la cual prosiguió en los días subsecuentes. El gobierno interino dio su anuencia para que las campañas prosiguieran, aunque sólo quedó un candidato: Obregón; jah! y uno nuevo que apareció de manera oportuna para darle esa aureola de legitimidad, necesaria tanto a la campaña como a las elecciones mismas, Alfredo Robles Domínguez. Aunque la presidencia ya se había ganado para Obregón. ${ }^{55}$

54 Excélsior, México, D.F., 23 de mayo de 1920

55 El proceso electoral no sólo son las elecciones, sino que también incluye la formación y acción de grupos y partidos políticos, la selección de candidatos y las campañas a nivel federal, estatal y regional. Meyer, Lorenzo, "La Revolución Mexicana y sus elecciones presidenciales: una interpretación (1911 1940)", Historia Mexicana, México, El Colegio de México, vol. 32, núm. 2, pp. 143-197. 


\section{LA CONTINUACIÓN DE LA CAMPAÑA}

El Plan de Agua Prieta había dado paso a un nuevo régimen que si bien no se contraponía con los emanados de la Revolución, debido a que en términos generales se mantenía en el marco que los demás gobiernos revolucionarios habían guardado hasta entonces, sí marcó un giro en cuanto al ascenso de una nueva clase política al poder.

Fue una coyuntura que acaeció en medio de la campaña electoral. Por tal situación, se suspendió la campaña electoral y, lo que es más importante, el panorama que ésta exhibía hasta entonces cambió de manera radical. En cuanto Venustiano Carranza, Pablo González e Ignacio Bonillas desaparecieron del mapa político, estos dos últimos personajes pasaron de tener un papel protagónico a ser exiliados políticos, mientras el otrora Jefe Máximo de la Revolución mexicana había perdido la vida. La prensa general, y Excélsior en particular, mostraron su desinterés hacia las elecciones después de lo acontecido en la rebelión de Agua Prieta. La noticia que se dio en diversos días fue la misma: el señor general Obregón continuaba su campaña afanosamente por todo el país. Excélsior publicó notas relativas a la campaña los días 28, 29 y 30 de agosto de 1920, donde Álvaro Obregón había recorrido grandes regiones del país por el norte, el sur, el sureste, el occidente y el pacífico. ${ }^{56}$ Estas notas estaban en columnas que denotan poca importancia. La campaña resultaba ya de poco interés para la opinión pública, al mismo tiempo que ésta lo avaló como candidato a presidente de la República.

En Excélsior ya había pocas noticias sobre la campaña, a lo más que se leía, en palabras que denotan gran respeto por el candidato en su campaña hacia la presidencia, es que:

El señor Obregón, candidato favorito según el sentir popular, ha realizado una extensa campaña por todo el país para de esta manera conocer los problemas y rezagos que tiene nuestro país. Esta labor la ha llevado a cabo después de recorrer a través del ferrocarril los diversos caminos tan difíciles que tiene la nación. Sin lugar a dudas esta campaña hará que conozca los problemas y ponga su esfuerzo en remediar los males de nuestra gran nación. ${ }^{57}$

56 Excélsior, México, D.F., 28, 29 y 30 de agosto de 1920.

57 Excélsior, México, D.F., 1 de septiembre de 1920. 
Excélsior publicó de manera constante imágenes a favor de Obregón, así lo mostró en una nota del día 3 de septiembre sobre quién era Alfredo Robles Domínguez y su trayectoria, ya que en tono sarcástico afirmó que era difícil encontrar referencias hacia el candidato del Partido Católico. ${ }^{58}$

El día 4 se dio a conocer en Excélsior, y en general en todos los diarios de la capital, la organización que se llevaría a cabo durante el ficticio ejercicio democrático que tanta sangre mexicana había costado. ${ }^{59}$ Finalmente, la campaña llegó a su fin el 5 de septiembre de 1920, día de las elecciones, el ganador no fue una sorpresa. Obregón había ganado en el campo de batalla. ${ }^{60}$

\section{REFLEXIONES FINALES}

A lo largo de este artículo se mostró la relación que mantuvo el "Manco de Celaya" con la prensa, particularmente con el diario capitalino Excélsior. La relación no estuvo exenta de altibajos, por el contrario, los constantes vaivenes que ocurrieron durante la campaña presidencial de Obregón de 1919 a 1920 provocaron que más de una vez Excélsior, y la prensa capitalina en general, tuvieran dudas en torno al futuro político del país. Por lo tanto, constantemente, dependiendo de los acontecimientos ocurridos en este breve lapso, las opiniones de los diarios cambiaron de un candidato a otro, sin perjudicar su relación con el régimen para no perder los derechos y privilegios alcanzados durante la Revolución de 1910, como una incipiente libertad de expresión e ingresos económicos por parte de distintos personajes políticos. El cambio se materializó cuando la dinastía sonorense comenzó a gobernar México y el Plan de Agua Prieta logró la transferencia de poder, la última transferencia violenta.

De esta forma, se mostró el buen manejo de la prensa que tuvieron Obregón y sus partidarios, pues no sólo se centró en su diario, El

58 Excélsior, México, D.F., 3 de septiembre de 1920

59 Excélsior, México, D.F., 4 de septiembre de 1920.

60 El caso de las elecciones llevadas a cabo en 1920 y 1922 a nivel federal son examinadas por MacGregor Campuzano, Javier, "Elecciones federales y transición a un nuevo régimen: México, 1920 y 1922. Estudios de caso", Historia Mexicana, México, El Colegio de México, vol. LX, núm. 2, 2010, pp. 1119-1174. 
Monitor Republicano, órgano de opinión publica del PLC, sino que trató de confeccionar una relación bastante nutrida y heterogénea con diferentes métodos que le diera dividendos políticos. Esto le funcionó, al mantener una buena relación con Excélsior, El Heraldo, El Monitor Republicano, La Prensa y El Universal. Obregón había hecho muy bien su labor, ya que la opinión pública formó una buena imagen de él hacia el interior y, no menos importante, hacia el exterior, lo cual le dio legitimidad al momento de acceder a la presidencia.

Las editoriales y las columnas de opinión de Excélsior, las cuales fueron las privilegiadas en este artículo, muestran que el diario de Rafael Alducín ayudó, mediante su pragmática postura, a confeccionar una opinión pública positiva hacia Álvaro Obregón. El antimilitarismo que usó el diario a favor del civilismo fue parte de una dinámica que ponderó el diario como el menor de los males para sus intereses económicos y políticos, a la vez que no renunció a denunciar que se buscara el desarrollo económico y estabilidad política en el país. Al darse cuenta que Obregón era el candidato con mayores posibilidades de ganar con los acontecimientos del Plan de Agua Prieta, el diario, como vocero y formador de la opinión pública, utilizó su pragmatismo para formar de él una imagen adecuada como el mejor candidato de entre los diversos personajes que buscaban acceder a la presidencia en 1920.

En resumen, las editoriales y las columnas de opinión de Excélsior y de otros diarios de la Ciudad de México y el interior de la República tienen importancia, ya que sirven como termómetro de un periódico. En ellas podemos ubicar su postura política-ideológica como transmisores y formadores de la opinión pública, y la utilidad política que tuvieron y tienen en la vida nacional. Ésta fue una de las lecciones mostradas por Álvaro Obregón a su grupo cercano, a saber: una relación con algún medio de información masiva que exponga y dé audiencia a su discurso, con el fin de crear una imagen de acuerdo a los intereses perseguidos. 


\section{FUENTES CONSULTADAS}

\section{Bibliografía}

Boladeras Cucurella, Margarita, "La opinión pública en Habermas", Análisis, Barcelona, Universitat de Barcelona, núm. 26, 2001, pp. 51-70. Castro, Pedro, Álvaro Obregón, México, Era-ConAculta, 2009.

Covo, Jacqueline, "La prensa en la Historiografía mexicana: problemas y perspectivas", Historia Mexicana, México, Colegio de México, vol. XLII, núm. 3, 1993, pp. 689- 701.

Del Palacio, Celia, "Cómo hacer historia de la prensa sin claudicar en el intento. Formas de hacer historia de la prensa en México", Acervos, México, AGN, núm. 30, otoño 2006-primavera 2007, pp. 4-14.

Dulles, John W. F., Ayer en México. Una crónica de la Revolución (1919-1936), México, Fondo de Cultura Económica, 2003.

Garciadiego Datan, Javier, “La Política militar del presidente Carranza”, en Hernández, Alicia y Manuel Miño Grijalva (coords.), Cincuenta años de historia de México, vol. 2, México, El Colegio de México, 1991, pp. 437-470.

Gómez Gil Rodríguez-Salas, María Luisa, "Círculos y canales de comunicación en el dominio de la ciencia”, Revista Mexicana de Sociología, México, UNAM, vol. 39, núm. 4, oct.-dic. 1997, pp. 1363-1395.

Habermas, Jürgen, Historia y crítica de la opinión pública. La transformación estructural de la vida pública, México y Barcelona, Editorial Gustavo Gili, 1990.

Koselleck, Reinhart, "Historia Magistra Vitae", en Futuro pasado. Para una semántica de los tiempos históricos, Madrid, Paidós, 1993, pp. 41-66.

MacGregor Campuzano, Javier, "Elecciones federales y transición a un nuevo régimen: México, 1920 y 1922. Estudios de caso”, Historia Mexicana, México, El Colegio de México, vol. LX, núm. 2, 2010, pp. 1119-1174.

Matute, Álvaro, "Prensa, sociedad y política (1911-1916)", en Cano, Aurora (coord.), Las publicaciones periódicas y la historia de México (ciclo de conferencias), México, UNAM, 1995, pp. 63-70.

Contraespionaje político y sucesión presidencial, México, UNAM, 1985.

Meyer, Jean, “El caudillismo electoral hasta 1929", en Medina Peña, Luis, El siglo del sufragio. De la reelección a la alternancia, México, Fondo de Cultura Económica-CONACYT, 2010, pp. 81- 114. 
"La Revolución Mexicana y sus elecciones presidenciales: una interpretación (1911-1940)". Historia Mexicana, México, El Colegio de México, vol. 32, núm. 2, pp. 143-197.

Obregón, Álvaro, "Manifiesto a la Nación (1 de junio de 1919)", en Iglesias González, Román (introducción y recopilación), Planes politicos, proclamas, manifiestos y otros documentos de la Independencia al México moderno, 1812-1940, México, UNAM, 1998 pp. 823-835.

Ocho mil kilómetros de campaña, México, Fondo de Cultura Económica, 1973.

Plata Aguilar, Blanca, "El imparcial: su oficio y su negocio", Revista mexicana de las ciencias sociales, México, UNAM, núm. 109, 1982, pp. 77-102.

Serna, Ana María, "Periodismo, Estado y opinión pública en los inicios de los años veinte (1919-1924)". Secuencia, México, Instituto Mora, mayo-agosto de 2007, pp. 57-85.

Suárez Escobar, Marcela, "Prensa e imagen. El crimen y su representación en la prensa mexicana a principios del siglo xx", en García de los Arcos, María Fernanda (coord.), La prensa como fuente para el análisis en las ciencias sociales, México, UAM-I, 2009, pp. 193-202.

Tamayo, Jaime, "Los ejes constitutivos del obregonismo: populismo, jacobinismo, socialismo y bonapartismo", Iztapalapa, México, UAM-I, núm. 32, ene.-jun. de 1994.

Tobler, Hans, La Revolución Mexicana. Transformación social y cambio político, 1876-1940, México, Alianza Editorial, 1994.

\section{Documentos de archivo}

Benjamín Hill a Álvaro Obregón, 20 de abril de 1919 en ACT, fondo 11, serie 020700, expediente H- 5/138, inv. 886.

\section{Hemerografía}

Excélsior, 1919-1920. 
